\title{
Attitudes and knowledge regarding health care policy and systems: a survey of medical students in Ontario and California
}

\author{
Sherif Emil MDCM, Justine M. Nagurney MD, Elise Mok PhD, Michael D. Prislin MD
}

Abstract

Background: Canada and the United States have similar medical education systems, but different health care systems. We surveyed medical students in Ontario and California to assess their knowledge and views about health care policy and systems, with an emphasis on attitudes toward universal care.

Methods: A web-based survey was administered during the 2010-2011 academic year to students in 5 medical schools in Ontario and 4 in California. The survey collected demographic data and evaluated attitudes and knowledge regarding broad health care policy issues and health care systems. An index of support for universal health care was created, and logistic regression models were used to examine potential determinants of such support.

Results: Responses were received from 2241 students: 1354 from Ontario and 887 from California, representing $42.9 \%$ of eligible respondents. Support for universal health care coverage was higher in Ontario (86.8\%) than in California $(51.1 \%), p<0.001$. In California, females, self-described nonconservatives, students with the intent to be involved in health care policy as physicians and students with a primary care orientation were associated with support for universal coverage. In Ontario, self-described liberals and accurate knowledge of the Canadian system were associated with support. A single-payer system for practice was preferred by $35.6 \%$ and $67.4 \%$ of students in California and Ontario, respectively. The quantity of instruction on health care policy in the curriculum was judged too little by $73.1 \%$ and $57.5 \%$ of students in California and Ontario, respectively.

Interpretation: Medical students in Ontario are substantially more supportive of universal access to health care than their California counterparts. A majority of students in both regions identified substantial curricular deficiencies in health care policy instruction.

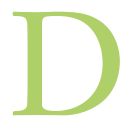
espite strong economic, political and cultural bonds, the United States and Canada have very different systems for health care delivery. The US has a multipayer system that left 48.6 million people, or $15.7 \%$ of the population, uninsured in 2011. ${ }^{1}$ Although there are many private insurers also operating in Canada, the majority of health care services are provided through a universal, publicly funded, provincially administered system that covers all citizens and legal residents. The system is commonly referred to as a single-payer system. Waiting periods for evaluation and treatment are common. In 2011, 2.8\% of Canadians waited for an estimated 941321 procedures. $^{2}$ Beyond insurance coverage and wait times, the differences between the 2 countries are shown in multiple aspects of health care, including physician and hospital reimbursement, administrative overhead, medical malpractice and availability of medical resources. Patients, as well as physicians, are affected by all of these factors.
Both countries are undergoing substantial transformations of their health care systems. In the US, the Patient Protection and Affordable Care Act, passed in 2010 and upheld by the US Supreme Court in 2012, seeks to expand health care coverage, constrain the growth in health care expenditures and improve the quality of care. Many doubt whether it can achieve all its goals, leaving substantial room for further reforms. ${ }^{3}$ In Canada, an important paradigm shift in health care has been advocated by the Canadian Medical Association, including establishment of a charter for patient-centred care, enhancing timely access to care and replacing global budgeting with activity-based funding. ${ }^{4}$

Competing interests: None declared.

Correspondence to: Sherif Emil, Sherif.Emil@McGill.ca

CMAJ Open 2014. DOI:10.9778/cmajo.20130094 
It is not clear when and how physicians formulate their beliefs and attitudes about health care policies and delivery systems. Recent reports have questioned the adequacy of health policy education in medical schools in the US. ${ }^{5,6}$ If medical students receive little formal education on health care policy, how do they formulate their positions on these issues? What global policies and overriding philosophies are they likely to support? As future physicians, are they equipped to help shape, let alone lead, the health care transformation? In this study, we investigated these questions broadly by surveying medical students in the most populous US state, California, and the most populous Canadian province, Ontario. The primary purpose of our study was to assess students' knowledge of and beliefs and attitudes toward broad health care provision principles and policies, constraint of health care costs and health care systems. Within this general framework, we focused on support for universal health care coverage in the 2 regions.

\section{Methods}

\section{Survey development}

Since no standardized or validated questionnaire existed, a new tool was developed, generating potential items based on a comprehensive literature review and discussions with experts in the field. ${ }^{7-11}$ The survey is provided in Appendix 1 (available at www.cmajopen.ca/content/2/4/E288/suppl/DC1) and consists of 4 sections: demographic information, future plans regarding engagement in health care policy issues, attitudes on issues addressed in health care policy and views regarding health care systems, and self-reported, as well as objective, measurement of knowledge regarding health care systems. Questions addressing the student's beliefs and attitudes used 5 -point Likert scales ranging from 1 (strongly agree) to 5 (strongly disagree). Questions assessing the student's objective knowledge of the American and Canadian health care delivery systems used a multiple choice format.

A draft survey was pilot-tested with a group of 20 medical students from the US and Canada who attended institutions not included in the study. The pilot testing was done to ensure that students responded to the intended referential and connotative meaning of each question, to assess reproducibility and to assess survey timing. Based on the comments from the pilot study, 2 questions were refined for clarity and 1 question was dropped. The final design was reviewed by a statistician.

\section{Participants}

The authors selected all 8 of the allopathic medical schools in California and 5 of the 6 medical schools in Ontario as potential sites for survey administration. The Northern Ontario School of Medicine was not invited to participate because the authors believed that its community-based medical education and specific social accountability mandate might result in an inherent bias. The schools participating in the survey were McMaster University, University of Ottawa, University of Toronto, Queen's University, Western Univer- sity, the University of California, Irvine, Loma Linda University, the University of California, Los Angeles and the University of California, Davis. All students were eligible to participate.

\section{Survey administration}

The survey was administered electronically using Survey Monkey during the 2010-2011 academic year. The survey link was emailed to the students by the office of the Assistant of Associate Dean for undergraduate education or student affairs in each medical school. Three reminders were sent by the investigators to the Deans' offices and forwarded to the students at approximately 2 -month intervals, with 1 final reminder 4 weeks before survey closure. Each school provided the investigators with the number of students to allow assessment of response rates.

\section{Statistical analysis}

Data are presented as proportions for categorical data and means (SD) for Likert scale questions. Differences in level of support for each statement between California and Ontario respondents were analyzed using a $t$ test. To determine predictors of support for universal health care among respondents in Ontario and California, we used 2 separate logistic regression models for each region. These variables are age (> 25 years), female, premedical degree, 3rd or 4th year in medical school, anticipated field of practice (primary care, nonprimary care or undecided), anticipated debt $>\$ 100$ 000, political self-characterization (very conservative or conservative, moderate, or liberal or very liberal), intent to be involved in health care policy as a physician, membership in organized medicine and accurate knowledge of health care systems (score of $100 \%$ on multiple choice questions). Students were considered supporters of universal health care if they agreed or strongly agreed with all of the following 3 statements:

- Access to health care is a fundamental human right.

- I plan to support universal health coverage as a physician.

- The government should guarantee health care access to all citizens.

Paired $t$ tests were used to assess changes in the mean rating of the students' self-reported understanding of health care systems, including their own and that of other countries, before starting medical school and at the time of the survey. All statistical analyses were performed using the Statistical Package for the Social Sciences (SPSS), version 20.0.

\section{Ethics approval}

The study was approved by the institutional review boards of the McGill University Faculty of Medicine (A07-E48-10B) and the University of California, Irvine School of Medicine (2010-7775). Four institutions accepted these approvals as sufficient, whereas 4 obtained internal approvals.

\section{Results}

A total of 5221 students were eligible to participate, 2058 in California and 3163 in Ontario. The survey was completed by 2241 students, a response rate of $42.9 \%$, nearly identical in 
both California (43.1\%) and Ontario (42.8\%). The distribution of respondents by year in medical school was as follows: first year, 31.4\%; second year, $27.7 \%$; third year, $22.5 \%$; and fourth year, $18.3 \%$; and did not differ between California and Ontario. The demographics and characteristics of responders are shown in Table 1. No data on nonrespondents were obtained.

The answers to Likert scale questions are shown in Table 2. Ontario respondents were consistently stronger supporters of a right to health care access and universal health care principles than their California counterparts. Support for a role for government in health care provision was also stronger in Ontario.

Respondents' choices of the best health care system to achieve intended outcomes are shown in Table 3.

Responses were analyzed to assess the progression of the students' self-reported understanding of their respective health care system, as well as other systems, since enrolment in medical school. For respondents from California, the mean (SD) score ( 1 = excellent and 4 = poor) of understanding their own and other health care systems over the time spent at medical school improved from $3.16(0.83)$ to $2.55(0.79)$ and from $3.46(0.75)$ to $3.09(0.81)$, respectively. For respondents from Ontario, the mean score of understanding their own and other health care systems improved from $2.79(0.79)$ to 2.17 (0.65) and from 3.35 (0.76) to 2.98 (0.77), respectively. All of these improvements were statistically significant, $p<0.0001$.

The quantity of instruction on health care policy was rated as "too little" by $73.1 \%$ of respondents from California and
$57.5 \%$ of respondents from Ontario. The quality of instruction on health care policy was rated as "excellent" or "good" by $26.5 \%$ of California respondents and $39.3 \%$ of Ontario respondents. The news media was the most common source of information about the student's respective health care system $37.9 \%$ of California respondents and $28.0 \%$ of Ontario respondents) and other health care systems (44.0\% of California respondents and $57.9 \%$ of Ontario respondents); the curriculum was one of the least common sources of information about the student's respective health care system $(8.0 \%$ of California respondents and $26.7 \%$ of Ontario respondents) and other health care systems $(6.7 \%$ of California respondents and $12.8 \%$ of Ontario respondents). A $100 \%$ score on questions pertaining to the US health care system was achieved by $37.3 \%$ of California respondents and $5.2 \%$ of Ontario respondents, whereas a $100 \%$ score on questions pertaining to the Canadian health care system was achieved by $37.3 \%$ of Ontario respondents and $10.6 \%$ of California respondents.

The regression analysis showed support for universal health care to be significantly higher in Ontario than in California (86.8\% v. $51.1 \%, p<0.001)$. Logistic regressions predicting support for universal health care coverage are shown in Table 4. Among California respondents, women, those with an intent to be involved in health care policy as a physician and selfdescribed nonconservatives were associated with increased support, whereas those with a nonprimary care orientation were less likely to support universal health care. Among

\begin{tabular}{|c|c|c|}
\hline \multirow[b]{2}{*}{ Characteristic } & \multicolumn{2}{|c|}{$\begin{array}{l}\text { Location of medical school; } \\
\text { no. of students }(\%)\end{array}$} \\
\hline & $\begin{array}{c}\text { California } \\
n=887\end{array}$ & $\begin{array}{c}\text { Ontario } \\
n=1354\end{array}$ \\
\hline Sex, female & 415 (47) & $819(61)$ \\
\hline \multicolumn{3}{|l|}{ Age, yr } \\
\hline $22-25$ & $507(57)$ & $848(63)$ \\
\hline $26-29$ & $255(29)$ & $343(25)$ \\
\hline \multicolumn{3}{|l|}{ Education, degree } \\
\hline Premedical & $887(100)$ & $1301(96)$ \\
\hline Masters & $76 \quad(9)$ & 261 (19) \\
\hline $\mathrm{PhD}$ & $18 \quad(2)$ & $51(4)$ \\
\hline Anticipated training in primary care & $251(28)$ & $504(37)$ \\
\hline Anticipated debt $>\$ 150000$ & $425(48)$ & $191(14)$ \\
\hline First- or second-degree family member physician & $381(43)$ & $494(37)$ \\
\hline \multicolumn{3}{|l|}{ Political views } \\
\hline Conservative or very conservative & $192(22)$ & $150(11)$ \\
\hline Moderate & $331(37)$ & $1164(29)$ \\
\hline Liberal or very liberal & $364(41)$ & $816(60)$ \\
\hline \multicolumn{3}{|l|}{ Role in organizations addressing health care policy } \\
\hline Member & $428(48)$ & $846(63)$ \\
\hline Leader & $72 \quad(8)$ & $38 \quad(3)$ \\
\hline
\end{tabular}


Ontario respondents, self-described liberals and those with an accurate knowledge of the Canadian system were associated with increased support for universal health care.

\section{Interpretation}

\section{Main findings}

The structure of medical education in Ontario and California is generally similar. However, in contrast to California, the majority of Ontario respondents were women and a larger proportion (almost 1 in 4) held graduate degrees. The debt burden was much lower for Ontario respondents. More than 1 in 3 of the Ontario respondents planned to pursue a primary care specialty, a proportion that is $30 \%$ higher than in California. Debt burden may potentially be implicated in these choices. In addition, the creation of patient-centred medical homes by the Ontario government has been shown to increase the percentage of medical students choosing primary care, as well as substantially increase the income of family physicians. ${ }^{12}$

At every level of the study, support for universal health care was substantially higher among Ontario respondents. The composite index included a fundamental value ("access to health care is a fundamental human right"), a personal commitment ("I plan to support universal health care coverage as a physician") and a policy proposition ("the government should guarantee health care access to all citizens"). Support as measured by this index was significantly higher among students in Ontario than those in California, 86.8\% v. $51.1 \%$. Among California respondents, female gender, an anticipated primary care field of practice and self-described liberal views represented determinants of support for universal health care. These 3 factors were substantially more prevalent in the Ontario cohort.

The single-payer system was chosen as the most favoured system in which to practice by a majority of Ontario respondents, and the most favoured system in which to be a patient by a smaller majority. Approximately one-third of California respondents also favoured the single-payer system for both. Ontario respondents also significantly preferred the singlepayer system for most patient-oriented outcomes. Interestingly, California respondents did not strongly prefer the multipayer system and, in many cases, rated the single-payer system higher. The knowledge deficit we identified may have affected system choice for some physician-oriented outcomes, such as micromanagement of physician decisions or financial conflicts of interest. The strengths of the single-payer system

\section{Table 2: Student responses to survey questions}

\begin{tabular}{|c|c|c|c|}
\hline \multirow[b]{2}{*}{ Future plans } & \multicolumn{2}{|c|}{$\begin{array}{l}\text { Location of medical school; } \\
\text { mean Likert scale score (SD) }\end{array}$} & \multirow[b]{2}{*}{$p$ value } \\
\hline & California & Ontario & \\
\hline I plan to become involved in health care policy as a physician & $2.49(0.93)$ & $2.52(0.92)$ & 0.52 \\
\hline I plan to take leadership in health care policy as a physician & $2.88(0.96)$ & $2.87(0.92)$ & 0.80 \\
\hline I plan to support universal health care coverage as a physician & $2.33(1.12)$ & $1.52(0.63)$ & $<0.001$ \\
\hline I do not expect to have time to be politically active as a physician & $3.21(1.02)$ & $3.27(0.92)$ & 0.15 \\
\hline \multicolumn{4}{|l|}{ Health care provision and policy } \\
\hline Access to health care is a fundamental human right & $2.04(1.20)$ & $1.35(0.64)$ & $<0.001$ \\
\hline The government should guarantee health care access for all citizens & $2.22(1.21)$ & $1.49(0.70)$ & $<0.001$ \\
\hline $\begin{array}{l}\text { The government should provide health care access for all citizens, even if } \\
\text { higher taxation is needed to generate sufficient revenue }\end{array}$ & $2.47(1.24)$ & $1.70(0.76)$ & $<0.001$ \\
\hline The government should regulate the prices of health care services & $2.66(1.19)$ & $1.97(0.87)$ & $<0.001$ \\
\hline $\begin{array}{l}\text { Health care services would improve if the government had no involvement in } \\
\text { health care }\end{array}$ & $3.74(1.09)$ & $4.19(0.80)$ & $<0.001$ \\
\hline $\begin{array}{l}\text { All citizens should have access to the same standard of medical care without } \\
\text { regard to their financial means }\end{array}$ & $2.44(1.23)$ & $1.71(0.10)$ & $<0.001$ \\
\hline $\begin{array}{l}\text { All children should have access to the same standard of medical care without } \\
\text { regard to their parents' financial means }\end{array}$ & $1.80(0.97)$ & $1.36(0.63)$ & $<0.001$ \\
\hline \multicolumn{4}{|l|}{ Control of medical costs: to constrain health care costs ... } \\
\hline Physicians should accept a cut in pay & $3.56(1.09)$ & $3.53(1.03)$ & 0.75 \\
\hline Insurance companies should lower their profit margin & $1.81(0.94)$ & $2.02(0.89)$ & $<0.001$ \\
\hline Drug companies should lower their prices & $2.01(0.99)$ & $2.01(0.89)$ & 0.91 \\
\hline Hospitals should decrease their operating costs & $2.47(0.96)$ & $2.78(1.01)$ & $<0.001$ \\
\hline Hospitals should not be operated for profit & $2.74(1.14)$ & $2.00(0.98)$ & $<0.001$ \\
\hline
\end{tabular}




\section{OPEN}

Research

in these areas may not have been evident to California respondents.

\section{Comparison with other studies}

A few studies in the US over the past 20 years have shared our purpose of elucidating the attitudes of medical students regarding health care delivery and, specifically, universal access. ${ }^{7-9}$ To our knowledge, this is the first study conducted in Canada. Previous American studies have demonstrated that medical students in the US largely favoured universal access, although the level of support varied. In 1994, a study of firstyear students in the University of California's 5 medical schools showed that two-thirds favoured a national health insurance plan. ${ }^{7}$ In 2006, Huebner and colleagues found overwhelming support for the principal of universal access, with $90 \%$ of first-year students and $88 \%$ of fourth-year students agreeing with the statement "everyone is entitled to adequate medical care regardless of ability to pay." However, a dichotomy was found between students' support for this principle and their support for models of reform that would achieve it. Support for such reform declined from $70 \%$ to $61 \%$ when first- and fourth-year students were polled. ${ }^{8}$ The influences that were most likely to create opposition to universal health care were residents, faculty and attending physicians, and opinions of family who were health professionals. ${ }^{8}$ Recently, Frank and colleagues found that support for universal health care decreased with progression in medical school. ${ }^{9}$ As in our study, predictors of support included female gender, a liberal political orientation and plans to pursue a primary care residency. ${ }^{9}$ Other studies have also shown that support for universal access and social justice principles in general, declines progressively during medical education. ${ }^{10,11}$ This decline continues after graduation. Physician surveys have shown less support for universal access legislation and, specifically, a single-payer system than student surveys. ${ }^{13-15}$

Whether the culture of many American medical schools promotes or discourages support for universal health care can be debated. However, most would agree that health policy education in North American medical schools is poor. , $, 6,16,17^{\text {In our }}$ study, only one-third of all respondents demonstrated accurate knowledge of the basics of their own health care system, and fewer than 1 in 10 respondents understood the basics of the

Table 3: Student responses to survey questions on choice of health care system to achieve intended outcome

\begin{tabular}{|c|c|c|c|c|c|c|}
\hline \multirow[b]{3}{*}{ Intended outcome } & \multirow{3}{*}{$\begin{array}{l}\text { Location } \\
\text { of medical } \\
\text { school }\end{array}$} & \multicolumn{5}{|c|}{ Percentage of respondents } \\
\hline & & \multicolumn{4}{|c|}{ Health care system } & \multirow[b]{2}{*}{$\begin{array}{l}\text { No } \\
\text { preference }\end{array}$} \\
\hline & & $\begin{array}{l}\text { Government } \\
\text { owned }\end{array}$ & Single payer & Multipayer & Private & \\
\hline \multirow[t]{2}{*}{ Access to care for everyone } & California & 43.0 & 33.0 & 18.4 & 1.9 & 3.6 \\
\hline & Ontario & 43.4 & 47.0 & 7.2 & 0.2 & 2.2 \\
\hline \multirow[t]{2}{*}{ Care of the highest quality } & California & 4.5 & 26.7 & 34.1 & 26.3 & 8.5 \\
\hline & Ontario & 8.6 & 40.3 & 28.9 & 15.4 & 6.8 \\
\hline \multirow{2}{*}{$\begin{array}{l}\text { Appropriate delivery of health care } \\
\text { services (i.e., avoidance of over- or } \\
\text { undertreatment) }\end{array}$} & California & 15.0 & 39.5 & 28.0 & 10.2 & 7.3 \\
\hline & Ontario & 20.9 & 53.2 & 18.9 & 2.5 & 4.5 \\
\hline \multirow[t]{2}{*}{ Prevention of illness or disease } & California & 20.1 & 39.1 & 23.0 & 6.8 & 11.0 \\
\hline & Ontario & 30.5 & 46.5 & 12.6 & 2.1 & 8.4 \\
\hline \multirow[t]{2}{*}{ Fostering technological innovation } & California & 5.0 & 12.5 & 31.2 & 42.8 & 8.5 \\
\hline & Ontario & 4.5 & 13.4 & 29.7 & 41.5 & 10.9 \\
\hline \multirow[t]{2}{*}{ Least waiting time for treatments } & California & 3.4 & 13.4 & 24.1 & 50.6 & 8.4 \\
\hline & Ontario & 5.4 & 13.5 & 35.7 & 37.3 & 8.2 \\
\hline \multirow[t]{2}{*}{ Freedom of choice for physician } & California & 5.6 & 16.6 & 24.4 & 44.0 & 9.5 \\
\hline & Ontario & 5.5 & 26.3 & 29.5 & 27.6 & 11.0 \\
\hline \multirow[t]{2}{*}{ Adequate physician income } & California & 3.9 & 15.3 & 27.6 & 38.1 & 15.2 \\
\hline & Ontario & 5.5 & 32.1 & 23.3 & 21.1 & 18.0 \\
\hline \multirow{2}{*}{$\begin{array}{l}\text { Least paperwork or bureaucratic } \\
\text { burden for physicians }\end{array}$} & California & 20.3 & 17.8 & 11.9 & 35.6 & 14.4 \\
\hline & Ontario & 24.3 & 22.3 & 8.5 & 22.2 & 22.7 \\
\hline \multirow{2}{*}{$\begin{array}{l}\text { Least interference with physicians' } \\
\text { decisions about patient care }\end{array}$} & California & 8.3 & 18.2 & 17.5 & 40.7 & 15.4 \\
\hline & Ontario & 10.8 & 36.0 & 11.2 & 26.4 & 15.7 \\
\hline \multirow{2}{*}{$\begin{array}{l}\text { Fewest potential financial conflicts of } \\
\text { interest for physicians }\end{array}$} & California & 38.3 & 25.1 & 14.4 & 10.9 & 11.2 \\
\hline & Ontario & 47.9 & 34.1 & 5.2 & 3.8 & 9.0 \\
\hline
\end{tabular}


neighbouring country's health care system. For example, less than $60 \%$ of California respondents correctly answered the question regarding the Patient Protection and Affordable Care Act of 2010, despite a recent survey showing that $80 \%$ of students are supportive of the law. ${ }^{18}$ A large majority of respondents in both locations rated the quantity of instruction on health care policy as too little, and a minority rated the quality as good or excellent. The medical curriculum ranked low as a source of information. These deficits have been consistently reported in previous medical student surveys. ${ }^{16,17}$ If students graduate without adequate knowledge of health care policy or alternative health care systems, they are unlikely to acquire that knowledge as physicians. Studies have shown that American physicians, both primary practitioners and specialists, have inaccurate impressions of the Canadian system. ${ }^{13,19}$ On the other hand, there is evidence that integration of instruction on health care policy into resident and student curricula results in increased knowledge, participation and action. ${ }^{17,18,20,21}$

Attitudes toward health care policy and preferences of health care systems by physicians are complex issues that may be affected more by personal values, culture and citizenship than by facts and figures. In a study of American and Canadian pediatric surgeons who trained or practised in both countries,
American surgeons preferred the US system by a 2:1 margin, whereas Canadian surgeons preferred their system by a $5: 1$ margin, despite direct exposure of the entire group to both systems. ${ }^{22}$ These differences persist from the individual physician level to the organizational level. The Canadian Medical Association has supported the Canada Health Act since its enactment; however, the American Medical Association has been opposed consistently to a similar system. ${ }^{4,23}$

\section{Study limitations}

Since the survey tool was specifically designed to gauge cross-border differences, validation on a large scale before its administration was not possible. To respect confidentiality, data on nonrespondents could not be obtained, presenting a potential selection bias. Because respondents may have been interested more in health care policy than nonrespondents, knowledge base and desire to be engaged in these issues may have been overestimated. Data also may not be nationally representative of the US or Canada, because the respondents are from a specific group of medical schools in specific regions of both countries. The survey was conducted during the 2010-2011 academic year. Over the last 3 years, the Canadian system has not changed much; however, the

\begin{tabular}{|c|c|c|}
\hline \multirow[b]{2}{*}{ Variable } & \multicolumn{2}{|c|}{$\begin{array}{l}\text { Location of medical school; } \\
\text { adjusted OR }(95 \% \mathrm{Cl})\end{array}$} \\
\hline & California & Ontario \\
\hline Age $>25 \mathrm{yr}$ & $0.90(0.60-1.34)$ & $1.01(0.63-1.63)$ \\
\hline Female & $1.54(1.09-2.19)^{\star}$ & $1.31(0.92-1.88)$ \\
\hline Premedical degree & $0.96(0.55-1.66)$ & $0.99(0.62-1.60)$ \\
\hline Third or fourth year in medical school & $0.76(0.51-1.12)$ & $0.94(0.63-1.40)$ \\
\hline \multicolumn{3}{|l|}{ Anticipated field } \\
\hline Primary care (reference) & 1.00 & 1.00 \\
\hline Nonprimary care & $0.55(0.36-0.83) \dagger$ & $0.71(0.47-1.06)$ \\
\hline Undecided & $0.45(0.28-0.72) \dagger$ & $0.84(0.51-1.39)$ \\
\hline Student debt $>\$ 100000$ & $1.29(0.89-1.87)$ & $1.13(0.78-1.62)$ \\
\hline Physician relative & $0.78(0.55-1.11)$ & $0.78(0.54-1.12)$ \\
\hline \multicolumn{3}{|l|}{ Political orientation } \\
\hline $\begin{array}{l}\text { Very conservative or conservative } \\
\text { (reference) }\end{array}$ & 1.00 & 1.00 \\
\hline Moderate & $6.28(3.65-10.81) \ddagger$ & $1.44(0.89-2.34)$ \\
\hline Liberal or very liberal & $31 \quad(7.45-55.08) \ddagger$ & $3.84(2.36-6.24) \ddagger$ \\
\hline Intent to be active in health policy & $1.81(1.26-2.58) \dagger$ & $0.93(0.65-1.33)$ \\
\hline Membership in organized medicine & $1.23(0.85-1.77)$ & $0.79(0.54-1.15)$ \\
\hline Accurate knowledge of US system & $0.95(0.66-1.37)$ & $0.64(0.32-1.28)$ \\
\hline Accurate knowledge of Canadian system & $0.84(0.47-1.50)$ & $1.73(1.18-2.55) \dagger$ \\
\hline $\begin{array}{l}\text { Note: } \mathrm{Cl}=\text { confidence interval, } \mathrm{OR}=\text { odds ratio of } \mathrm{s} \\
{ }^{*} p<0.05 . \\
\dagger p<0.01 . \\
\ddagger p<0.001 .\end{array}$ & r universal health care co & \\
\hline
\end{tabular}


Patient Care and Affordable Care Act was implemented in the US during this time period amid much controversy, which may render the results reported from students in California not representative of the current student cohort.

\section{Conclusion}

The differences in health care systems between the US and Canada are deep-rooted and embedded in the history, politics and cultural traditions of both countries. These differences were reflected in our comparison of Ontario and California medical students. The differences in the level of physician support for universal access to health care between Ontario and California start in medical school. Many of these views, which are embedded early in a physician's formative experience, are based on inadequate knowledge of health care systems. Like many, we believe that medical schools and academic medicine in general have a responsibility to train socially responsible physicians who will advocate for universal health care access of appropriate quality and cost. This can only be achieved if highquality and sufficient quantity instruction on health care policy and health care systems is integrated into medical school curricula in the US and Canada, a challenge yet to be met.

\section{References}

1. DeNavas-Walt C, Proctor BD, Smith JC. Income, poverty, and health insurance coverage in the United States: 2011. Washington: US Census Bureau; 2012. Available: www.census.gov/prod/2012pubs/p60-243.pdf (accessed 2014 Aug. 29).

2. Barua B, Rovere M, Skinner BJ. Waiting your turn: wait times for bealth care in Canada. 2011 report. Vancouver: Fraser Institute Studies in Health Policy; 2011. Available: www.fraserinstitute.org/uploadedFiles/fraser-ca/Content /research-news/research/publications/waiting-your-turn-2011.pdf (accessed 2014 Aug. 29).

3. Wilensky GR. The shortfalls of "Obamacare". N Engl 7 Med 2012;367:1479-81.

4. Health care transformation in Canada. Ottawa: Canadian Medical Association; 2010.

5. Patel MS, Davis MM, Lypson ML. Advancing medical education by teaching health policy. N Engl 7 Med 2011;364:695-7.

6. Mou D, Sarma A, Sethi R, et al. The state of health policy education in US medical schools. N Engl 7 Med 2011;364:e19.

7. Wilkes MS, Skootsky SA, Hodgson CS, et al. Health care reform as perceived by first year medical students. F Community Health 1994;19:253-69.

8. Huebner J, Agrawal JR, Sehgai AR, et al. Universal health care and reform of the health care system: views of medical students in the United States. Acad Med 2006;81:721-7.

9. Frank E, Modi S, Elon L, et al. US medical students' attitudes about patients' access to care. Prev Med 2008;47:140-5.

10. Maheux B, Beland F. Changes in students' sociopolitical attitudes during medical school: Socialization or maturation effect? Soc Sci Med 1987;24: 619-24.

11. Maheux B, Beland F, Pineault R. The influence of medical school program on physicians' attitudes toward universal access to medical care. Med Care 1987;25:202-9.

12. Rosser WW, Colwill JM, Kasperski J, et al. Patient-centered medical homes in Ontario. N Engl 7 Med 2010;362:e7.

13. Scanlan A, Zyzanski SJ, Flocke SA, et al. A comparison of US and Canadian family physician attitudes toward their respective health-care systems. Med Care 1996;34:837-44.

14. Ackermann RT, Carroll AE. Support for national health insurance among US physicians: a national survey. Ann Intern Med 2003;139:795-801.

15. McCormick D, Himmelstein DU, Woolhandler S, et al. Single-payer national health insurance. Physicians' views. Arch Intern Med 2004;164:300-4.

16. Agrawal JR, Huebner J, Hedgecock J, et al. Medical students' knowledge of the US health care system and their preferences for curricular change; a national survey. Acad Med 2005;80:484-8.

17. Patel MS, Lypson ML, Davis MM. Medical student perceptions of education in health care systems. Acad Med 2009;84:1301-6.

18. Huntoon KM, McCluney CJ, Scannell CA, et al. Health care reform and the next generation: United States medical student attitudes toward the patient protection and affordable care act. PLoS ONE 2011;6:e23557.

19. Nakayama DK, Langer JC. Single payer health insurance in pediatric surgery: US impressions and Canadian experience. Pediatr Surg Int 2011; 27:329-34.

20. Quraishi SA, Okin FK, Weitekamp MR, et al. The health policy and legislative awareness initiative at the Pennsylvania State University College of Medicine: theory meets practice. Acad Med 2005;80:443-7.

21. Jacobsohn V, DeArman M, Moran P, et al. Changing hospital policy from the wards: an introduction to health policy education. Acad Med 2008; 83:352-6.

22. Emil S, Laberge J-M. Canada-trained pediatric surgeons: a cross-border survey of satisfaction and preferences. F Pediatr Surg 2007;42:878-84.

23. Health Policy Group. Expanding health insurance: the AMA proposal for reform [proposal]. Chicago: American Medical Association; 2005.

Affiliations: Department of Pediatric Surgery (Emil), Faculty of Medicine, McGill University, Montréal, Que.; Faculty of Medicine (Nagurney), McGill University, Montréal, Que.; Clinical Research Center (Mok), The Montreal Children's Hospital, McGill University Health Centre, Montréal, Que.; Department of Family Medicine (Prislin), School of Medicine, University of California, Irvine, Irvine, Calif.

Contributors: All of the authors contributed to the conception and design of the study and the analysis and interpretation of the data, revised the manuscript critically for important intellectual content and approved the final version of the manuscript submitted for publication.

Funding: Justine Nagurney was supported as a medical student by the Sir Edward W. Beatty Memorial Scholarship, a bursary that supports the research efforts of undergraduate and graduate students in the Faculty of Medicine at McGill University.

Supplemental information: For reviewer comments and the original submission of this manuscript, please see www.cmajopen.ca/content/2/4 /E288/suppl/DC1 